Ragweed pollen: is climate change creating a new aeroallergen problem in the UK?

C. H. Pashley, J. Satchwell and R. E. Edwards

Institute for Lung Health, Department of Infection, Immunity and Inflammation, University of Leicester, Leicester, United Kingdom.

Running title: Ragweed pollen in the UK

Corresponding author: Dr Catherine H. Pashley

Aerobiology \& clinical mycology

Department of Infection, Immunity and Inflammation

University of Leicester

University Road

Leicester

LE1 9HN

UK

Email: chp5@le.ac.uk

Tel: +44 (0) 1162522936

Fax: +44 (0) 1162525030 


\section{Ragweed pollen: is climate change creating a new aeroallergen problem in the UK?}

\section{Introduction}

Ragweeds are probably the most well-known hayfever triggers in North America and are becoming notorious within certain areas of Europe. Ragweeds are found within the genus Ambrosia, a group of about 40 plants within the family Asteraceae, most of which are native to North America. The two most well known species are the common ragweed (also known as the short ragweed) $A$. artemisiifolia and the giant ragweed $A$. trifida; with the common ragweed being the most widespread and important in terms of allergy. Both are annual plants with a tendency to become pernicious weeds. They have inconspicuous greenish flowers that are borne in small heads (Fig. 1 inset). The male flowers produce a large number of fairly small $(18-22 \mu \mathrm{m})$ wind dispersed pollen grains that can be carried long distances [1].They were introduced to Europe in the $19^{\text {th }}$ Century, spreading rapidly after 1940 . The three main sources of ragweed in Europe are 1) the Pannonian Plain in Central Europe including Hungary and neighbouring countries, 2) the Rhône Valley in France, and 3) Northern Italy [2]. In the UK it is classed as a casual plant, i.e. one that is introduced, often through contaminated bird seed, but is not naturalised and rarely persists.

Ragweed is one of the major causes of sensitisation in the general population in North America thought to affect approximately $26 \%$ of the US population. Ragweed is also a potent aeroallergen in Europe, in particular in Eastern Europe, France and Italy. The threshold for clinical symptoms is believed to be as low as 1-3 ragweed pollen grains $/ \mathrm{m}^{3}$ air based on a study from Canada over two seasons [3], which is lower than the threshold for other well known pollen allergens such as grass (50 grains) and birch ( 80 grains). The prevalence of ragweed sensitisation in many European countries is above $2.5 \%$, being highest in Hungary (>50\%) and Denmark (19.8\%) [4], although in Denmark sensitisation is likely to reflect cross-sensitisation with Ambrosia pollen. Ambrosia, a genus which includes mugwort, wormwood and sagebrush, is a fellow member of the family Asteraceae and cross-reaction and concomitant sensitisation is known to occur between the two genera [1]. Of those individuals who are sensitised to ragweed, nearly a quarter show asthma symptoms. 
Corresponding to the scarcity of ragweed plants in the UK, ragweed pollen is rarely seen in UK pollen counts. In 2014 ragweed pollen was observed in surprising quantities at a site in the centre of England, Leicester. This study compares ragweed pollen levels in this area since 1970 and discusses whether this was an isolated phenomenon or the start of a trend caused by the changing climate that could see the hayfever season extending into the autumn.

\section{Methods}

Atmospheric pollen has been recorded in the East midlands since 1970. Pollen traps were running in Derby between 1970 and 2008 and in Leicester from 1990 to the present day. A study comparing the pollen counts between the two sites found that counts from the abundant pollen-types were highly correlated, and suggested that a forecast based on data from a single site would be suitable for forecasting for both [5].

Air was sampled using seven-day recording volumetric spore traps (Burkard manufacturing Co. Ltd). Ragweed pollen is identified by morphology microscopically (Fig. 2 inset) according to British Aerobiology Federation standardised techniques whereby 12 equidistant transverse traverses are counted. Pollen concentrations were expressed as average number of pollen grains per cubic metre of air per day (grains $\mathrm{m}^{-3}$ air day ${ }^{-1}$ ).

\section{Results}

The main ragweed pollen season is from mid August to end of September. Pollen data was missing for these months from 1986, so this year was omitted from this study. All years included in this study had daily average pollen concentrations available from the $1^{\text {st }}$ June to 30 th September resulting in 44 years available for comparison. Ragweed pollen has been observed during 7 of the 44 years for which data is available (Table 1). Other than 2014 , the maximum daily average concentration on any given day, or in any given year, was 5 . In contrast the sum of the daily average counts for 2014 was 56, peaking at a maximum daily average concentration of 35. Ragweed was observed on 9 days, with the majority (91\%) being recorded on the four days between the third and sixth of September (Fig. 1). 
During those four days the time periods with the highest concentrations of ragweed pollen were 8 pm to 2 am on the night of the $4^{\text {th }}$ to $5^{\text {th }}$ September, and 8 am to $2 \mathrm{pm}$ on the $5^{\text {th }}$ September (Fig. 2) with the strongest 2 hour periods being midnight to 2 am and midday to $2 \mathrm{pm}$.

\section{Discussion}

Hayfever is one of the most common allergic conditions, with more than 10 million estimated sufferers in the UK alone. Pollen can also trigger asthma in sensitised individuals. Grass pollen is the major cause of pollinosis in many parts of the world, and although its frequency varies between countries, grass-induced allergies are the most common pollen allergy in Europe [6] including in the UK. The naturalisation of ragweed plants in the UK is of a great health concern to the allergic population. Less than 20 years since its appearance in Northern Italy, ragweed pollen has become the second most frequent cause of respiratory allergy and the one causing the most symptoms and has been responsible for de novo sensitisation in older individuals [7].

There is growing evidence to suggest climate change will facilitate the geographical spread of particular plant species to new areas [6]. Ragweed seed production occurs in October and the beginning of November; which means ragweed plants require long-lasting autumns before the first frost to allow their seeds to mature, limiting their northward distribution in Europe. In the 1990s, based on the UK Met Office climate predictions models, it was suggested that ragweed could spread north and be persistent as far as central England by the year 2050. More recently a process-based model of weed growth, competition and population dynamics has been used to predict the future potential for range expansion under climate change scenarios. Suitable habitat was predicted to extend further north and east such that populations in Scandinavian countries and Britain that are currently classed as casual may become established [2]. This could cause serious health problems in areas where Ambrosia pollen concentrations are currently below the threshold for inducing clinical symptoms. Furthermore, cross-reactivity with Artemisia pollen, known to be an important aeroallergen in some parts of Northern Europe, would exacerbate the risk of health problems. In some areas increase in ragweed hypersensitivity has been paralleled by a similar increase in the 
prevalence of Artemisia sensitisation, even though Artemisia had always been present in the area and Artemisia pollen levels did not rise [8]. This may not pose too great a risk in the UK, where Artemisia pollen counts are amongst the lowest in Europe [9].

There are two scenarios that could have resulted in the ragweed peak observed in Leicester on the fourth and fifth of September; local ragweed plants releasing pollen and long distance transport from mainland Europe via wind. According to the species accounts of the BSBI (Botanical Society of the British Isles), if $A$. artemisiifolia were a native plant it would be classed as nationally scarce. They suggest it is increasing in range and probably in abundance, possibly because there are more people putting out bird seed, but that the plants rarely persist. According to the Met Office 2014 was the third warmest autumn since 1910, just behind 2006 and 2011, suggesting that the UK may be moving towards the type of climate that would allow ragweed to naturalise.

There are many examples of pollen traveling long distances, and there is evidence to suggest that ragweed pollen has been involved in long distance travel within Europe, even to the extent where it can reach clinical thresholds [6].Pollen release starts with ragweed anthers extending and opening between 6.30 and 8 am, when temperature is increasing and humidity decreasing. This pattern causes a morning peak in ragweed concentrations from about $6.30 \mathrm{am}$ to around midday in the local area. The time the pollen is recorded at a pollen monitoring site will depend upon how far the sampler is from the source and the wind speed [1]. In this study the strongest peak was 8 am to 2 pm which could represent a local population and support the argument that climate change is enabling ragweed to establish itself in the UK, or it could indicate a long transport time (e.g. 24 hours) from a large source such as the Pannonian Plain. There was also a strong peak in the middle of the night suggesting, at least in part,the source of the pollen was a distance away. It is plausible that the pollen observed was caused by a combination of local and distant sources. To address this further would require data from other UK sites, which unfortunately are not available as the UK pollen network cease counting at the end of August, or a study examining atmospheric transport of 
Ambrosia pollen using wind-trajectories on a European scale, which is beyond the scope of this letter.

The ragweed pollen reached levels high enough to have caused clinical symptoms in sensitised individuals; however, rates of sensitisation in the UK are currently low. The experience from Italy and other European countries has been that the onset in time between ragweed arriving in the area and high proportions of the population becoming sensitised and going on to develop clinical symptoms is fairly short (as little as 20 years) [7]. If climate changes as predicted, and if the predicted spread of ragweed occurs, clinicians in the UK will need to be aware of the potential for ragweed pollen allergy during autumn, a time of year when most people assume hayfever is over. This study suggests that current predictions may be right, and likely represents an example of the effects of climate change posing a threat to human health.

\section{Acknowledgements}

Historical pollen data was kindly provided by the Midlands Asthma and Allergy Research Association (MAARA). We would particularly like to thank pollen counters Julie Corden, Wendy Millington, Felicity Jackson and Abbie Fairs for their contributions. Thanks also to Dr John Bailey for providing the photo of ragweed in Hungary. Support has come from MAARA and the National Institute for Health Research Leicester Respiratory Biomedical Research Unit. The views expressed are those of the authors and not necessarily those of the NHS, the NIHR or the Department of Health.

\section{Conflicts of interests}

The authors declare no conflict of interest.

\section{References}

1. Smith M, Cecchi L, Skjoth CA, Karrer G, Sikoparija B, Common ragweed: a threat to environmental health in Europe. Environ Int 2013;61: 115-26. 
2. Storkey J, Stratonovitch P, Chapman DS, Vidotto F, Semenov MA, A process-based approach to predicting the effect of climate change on the distribution of an invasive allergenic plant in Europe. Plos One 2014;9: e88156.

3. de Weger LA, Bergmann KC, Rantio-Lehtimäki A, Dahl Å, Buters J, Déchamp C, Belmonte J, Thibaudon M, Cecchi L, Besancenot J-P, Galán C, Waisel Y, Impact of pollen. In: Sofiev M, Bergmann K-C eds. Allergenic Pollen: a review of the production, release, distribution and health impacts. Dordrecht: Springer 2013:161-215.

4. Burbach GJ, Heinzerling LM, Rohnelt C, Bergmann KC, Behrendt $\mathrm{H}$, Zuberbier T, study G, Ragweed sensitization in Europe - GA(2)LEN study suggests increasing prevalence. Allergy 2009;64: 664-5.

5. Pashley CH, Fairs A, Edwards RE, Bailey JP, Corden JM, Wardlaw AJ, Reproducibility between counts of airborne allergenic pollen from two cities in the East Midlands, UK. Aerobiologia 2009;25: 249-63.

6. D'Amato G, Cecchi L, Bonini S, Nunes C, Annesi-Maesano I, Behrendt H, Liccardi G, Popov T, van Cauwenberge P, Allergenic pollen and pollen allergy in Europe. Allergy 2007;62: 976-90.

7. Asero R, Ragweed allergy in northern Italy: are patterns of sensitization changing? Eur Ann Allergy Clin Immunol 2012;44: 157-9.

8. Asero R, Wopfner N, Gruber P, Gadermaier G, Ferreira F, Artemisia and Ambrosia hypersensitivity: co-sensitization or co-recognition? Clini Exp Allergy 2006;36: 658-65.

9. Smith M, Jaeger S, Berger U, Sikoparija B, Hallsdottir M, Sauliene I, Bergmann KC, Pashley CH, de Weger L, Majkowska-Wojciechowska B, Rybnicek O, Thibaudon M, Gehrig R, Bonini M, Yankova R, Damialis A, Vokou D, Gutierrez Bustillo AM, Hoffmann-Sommergruber K, van Ree R, Geographic and temporal variations in pollen exposure across Europe. Allergy 2014;69: 913-23. 


\section{Figure legends}

Fig. 1. Distribution of average ragweed pollen concentrations in 2014. Inset, Ambrosia artemisiifolia growing in Hungary.

Fig. 2. Time periods during which ragweed pollen was observed on the $3^{\text {rd }}$ to $6^{\text {th }}$ September 2014 . Inset, Ambrosia pollen captured on $5^{\text {th }}$ September 2014, viewed at $x 630$ magnification. Scale bar represents $10 \mu \mathrm{m}$. 


\begin{tabular}{cccc}
\hline Year & Total abundance & Maximum daily average & Number of days \\
\hline 1992 & 5 & 5 & 1 \\
1999 & 5 & 1 & 5 \\
2005 & 2 & 1 & 2 \\
2006 & 5 & 2 & 3 \\
2007 & 1 & 1 & 1 \\
2009 & 1 & 1 & 1 \\
2014 & 56 & 35 & 9
\end{tabular}

Table 1. Years during which ragweed pollen was recorded, the total abundance reported as the sum of the daily averages recorded that year, the maximum daily average concentration and the number of days on which pollen was observed. 